\title{
MULTI-TEMPORAL ANALYSIS OF DENSE AND SPARSE FORESTS' RADAR BACKSCATTER USING SENTINEL-1A COLLECTION IN GOOGLE EARTH ENGINE
}

\author{
C. M. Arellano ${ }^{1 *}$, A. A. Maralit ${ }^{1}$, E. C. Paringit ${ }^{1}$, C. J. Sarmiento ${ }^{1}$, R. A. Faelga ${ }^{1}$, F. A. Tandoc ${ }^{1}$, C. Vidad $^{1}$, R. Lopez ${ }^{1}$, F. J. \\ Pamittan ${ }^{1}$ \\ ${ }^{1}$ Training Center for Applied Geodesy and Photogrammetry, College of Engineering, University of the Philippines, Diliman, \\ Quezon City, 1101, Philippines - (cmarellano, cssarmiento, fopamittan)@ up.edu.ph, (aeronadrianmaralit, paringit, reginefaelga, \\ tandoc.fe, celeste.z.vidad, rusty.lpz)@gmail.com
}

\section{Commission IV}

KEY WORDS: Forest, Synthetic Aperture Radar (SAR), Sentinel-1A, Google Earth Engine

\begin{abstract}
:
Radar data has been historically expensive and complex to process. However, in this milieu of cloud-computing platforms and opensource datasets, radar data analysis has become convenient and can now be performed for more exploratory researches. This study aims to perform multi-temporal analysis of radar backscatter to characterize dense and sparse forest from Sentinel-1 images. The area of study are reforested sites under the National Greening Program (NGP) of the Philippines. Ground data were collected: (1) in 2019, from a 1.35 ha -site in Brgy. Calula, Ipil, Zamboanga Sibugay, (2) in 2019, from a 1.10 ha- site in Brgy. Cabatuanan, Basay, Negros Oriental, and (3) from PhilLiDAR 2 - Project 3: FRExLS' 2.4 ha -validated site in Ubay, Bohol. SAR intensity values were derived from Sentinel-1 from Google Earth Engine, which is a cloud-based platform with a repository of satellite images and functionalities for data extraction and processing. The temporal variation in C-band radar backscatter from 2014 to 2018 were analyzed. The results show, for the whole period of analysis, that: in VH polarization, dense forest samples backscatter range from 11 to $-18 \mathrm{~dB}$ in $\mathrm{VH}$ and -2 to $-13 \mathrm{~dB}$ in $\mathrm{VV}$; sparse forest samples range from -12 to $-21 \mathrm{~dB}$ in $\mathrm{VH}$ and -7 to $-14 \mathrm{~dB}$ in $\mathrm{VV}$; ground samples range from -12 to $-24 \mathrm{~dB}$ in $\mathrm{VH}$ and -6 to $-15 \mathrm{~dB}$ in $\mathrm{VV}$; and water samples range from -21 to $-30 \mathrm{~dB}$ in $\mathrm{VH}$ and -11 to -26 $\mathrm{dB}$ in VV. Forest backscatter are expected to saturate over time, especially in dense forests. These variations are due to differences in forest species, landscape, environmental and climatic drivers, and phenomenon or interventions on the site.
\end{abstract}

\section{INTRODUCTION}

Remote Sensing (RS) is both a technology and science, used to observe, measure, and map objects on Earth's surface from a distance. Through the years, it has been the focus of a lot of research and development works in terms of sensors, processing, simulation, and analysis according to CIFOR (2010) One of the key applications of RS is in the field of forestry. RS techniques such as forest classification and mapping contribute to forest management, inventory, and understanding. Forest loss due to deforestation and degradation can now be easily detected. Forest resource information can be inventoried without laboriously taking direct measurements on the field. Spatial variations in physiological characteristics, productivity, successional patterns, forest structure, and forest decline can also be analyzed. White, et al., (2016) has shown that the wealth of remotely-sensed data complemented by advanced remote sensing techniques contribute towards accurately and efficiently determining forest information for strategic planning and management.

There is a need for temporal, spatial, and thematic forest information because of their role in global carbon balance and sustainable social, economic, and ecological development. RS has been used for decades for national forest inventories. Different types of satellite data have different uses and different drawbacks. Active RS technologies, such as Synthetic Aperture Radar (SAR), has been widely used nowadays as it provides new opportunities for global forest monitoring and inventory, in a cost-efficient manner, as mentioned by Tomppo, Praks, Wang, \& Waser, (2019)
SAR sensors operate at microwave spectrum; hence, it can penetrate through clouds and is not affected by weather conditions. An example of SAR data is from European Space Agency's (ESA) Sentinel-1A which acquires a cloud-free satellite image every 12-days. Using in conjunction with data from Sentinel 1-B which also acquire data every 12 days, users technically have data every 6 days. However, radar data has been historically complex to process and analyze. Summarized by Walker (2016), depending on the application, system parameters such as sensor wavelength (X-, C-, L-, or P - band), polarization $(\mathrm{HH}, \mathrm{HV}, \mathrm{VH}, \mathrm{VV})$, incidence angle, and resolution; and target parameters such as structure (size, orientation, and distribution of scattering surfaces), surface roughness, moisture content, and slope orientation, must be taken into account when choosing what data and approach to use.

SAR is sensitive to biophysical parameters and dynamics of vegetation, as well as the underlying parameters on the ground such as dielectric constant, geometry, deflection and irregularity, soil surface roughness, and water content, as shown by Nasirzadehdizaji, et al., (2019). Different applications of SAR in forestry include mapping of forest cover; mapping and analysis of forest structural attributes such as height, basal area, biomass and volume; monitoring disturbances such as widespread logging and forest fires; change detection for cases of deforestation and degradation; and monitoring of forest growth and regrowth. The applications supported by a SAR sensor, however, depend on the frequency used. 
SERVIR, (2019) has summarized the applications of different wavelengths. Ka-, Ku-, and $\mathrm{X}$ - have high frequencies (27-40 $\mathrm{GHz}, 18-27 \mathrm{GHz}, 12-18 \mathrm{GHz})$ and shorter wavelengths (1.1-0.8 $\mathrm{cm}, 1.7-1.1 \mathrm{~cm}, 2.4-1.7 \mathrm{~cm})$, which are rarely used for SAR remote sensing. Most space borne sensors use lower frequency bands with longer wavelength from $\mathrm{X}$ - to $\mathrm{P}$ - band, as the wavelength of a SAR sensor is linked to the penetration capabilities of the transmitted microwave signal. Longer wavelengths such as $\mathrm{P}$ - and L- band penetrate deeper into canopies and soils. X- band $(8-12 \mathrm{GHz}, 3.8-2.4 \mathrm{~cm})$ SAR are of high-resolution, but are more suitable for urban and built-up monitoring. They are rarely used for characterizing forests as they have limited penetration and fast coherence decay into vegetation cover. C- band $(4-5 \mathrm{GHz}, 7.5-3.8 \mathrm{~cm}) \mathrm{SAR}$ are of moderate to high resolution with increased vegetation penetration. There are a lot of SAR systems operating at this range because it is seen as a good compromise between $\mathrm{X}$ - band and longer wavelength $\mathrm{L}$ - band, and it allows wide swath imaging applicable for large-scale applications. There are very little but increasing use of S- band $(2-4 \mathrm{GHz}, 15-7.5 \mathrm{~cm}) \mathrm{SAR}$. A lot of developments are still underway for this range. S-band NovaSAR has been recently deployed in 2018. L- band (1-2 $\mathrm{GHz}, 30-15 \mathrm{~cm}) \mathrm{SAR}$, on the other hand, are of medium resolution, but their shorter wavelengths allow high canopy penetration capabilities. L- band SARs are very useful for characterizing canopy and undergrowth structures, especially in dense forests. Because of these capabilities, a lot of development towards the future of SAR are focused on the Lband range. Lastly, P- band $(0.3-1 \mathrm{GHz}, 100-30 \mathrm{~cm})$ SAR are also under development since this frequency is affected by ionospheric distortions. The first P- band space borne SAR, ESA's Biomass, will be launched in 2020, and is aimed to focus on mapping the distribution and changes in biomass of Earth's forests.

Previous SAR studies mostly focused on forest classification, forest biomass estimation, and forest structure analysis. Vyjayanthi, et al. (2008) have studied the SAR interaction with deciduous vegetation using advanced polarimetric and interferometric techniques on air-borne DLR-ESAR and spaceborne C-band ENVISAT-ASAR data. Their team acquired polarimetric signatures from L-band DLR-ESAR data for different vegetation types, the knowledge of which will aid in their qualitative assessment of forest resources. Their results show that bamboo exhibit double bounce, teak exhibit single bounce, and plantation exhibit corner reflector scattering mechanisms. They have also analyzed variations in backscattering coefficients in different polarizations $(\mathrm{HH}, \mathrm{VH}$, $\mathrm{HV}$, and VV) and found VV to have significant variations. As they were comparing the results from C-, L- and P- bands of DLR-ESAR, they found out that at lower frequency $(\mathrm{P}-$ and $\mathrm{L}$ band), the branches and trunks of the trees are dominant scatterers. But as the frequency increased, like in C-band, the effects of the leaves or the canopy are main backscatter contributor. The study of Dostalova, Milenkovic, Hollaus, and Wagner (2016) analyzed the seasonal variability of forest backscatter from dual-polarized Sentinel-1 data. They have studied backscatter variation and analyzed them with respect to forest type (coniferous, deciduous, and mixed), forest cover fraction, height, and structure. Forest cover information were derived from full-waveform airborne laser scanning (ALS) LiDAR data, collected with Riegl LMS-Q560 and LM-Q680. Forest height was derived from the generated normalized digital surface model (nDSM). Forest structure, represented by the vegetation amplitude fraction, was derived from the generated digital terrain model (DTM). In the study, they have shown that forest structure have an influence on backscatter seasonality as exhibited by the backscatter values of coniferous and mixed forests in summer and winter in Austria. Forest height has an overall very minimal influence on the backscatter, while forest cover fraction and type have the strongest influence on the backscatter of deciduous forests.

A lot of SAR remote sensing time series analysis are still being developed as the demand for global data sets increase. These are also influenced by the increase in available satellite data archives. Time Series analysis are valuable in understanding the processess, which are very helpful in modelling and calibration. However, exponentially growing data volumes require big data processing infrastructures, as mentioned by Wagner, (2016). In the private sector, examples of big data infrastructures are Google Earth Engine, Amazon Web Services, and Helix Nebula Science Cloud. In the public sector, initiatives for big data infrastructures are triggered mostly by national space programmes such as THEIA Land Data Centre (France), OPUS/Copernicus Centre (Germany), and European Space Agency mission platforms. Wagner (2016) has also summarized some applications from time series analysis of Sentinel-1 data, as processed on high performance computing platforms. Related to forest mapping, forest area were derived from Sentinel-1 images from January 2014 to March 2015, and seasonal backscatter signal over forest were analyzed from January 2015 to May 2016, by Dostalova, Milenkovic, Hollaus, \& Wagner, (2016).

This study aims to characterize dense and sparse forest from multi-temporal radar backscatter from Sentinel-1A images. The objective of this study is to determine the separability and variability of dense and sparse forests of C-band radar temporal signature. The sites used in the study are reforestation sites from the Philippine's National Greening Program (NGP) which started in 2011. Sentinel-1A data was used because they are freely-available and temporally dense with medium-scale images acquired every 12 days from 2014. To process such huge data from 2014, on the context that SAR data are of big file sizes (one scene is typically $\sim 900 \mathrm{MB}$ ), high performance computing resources would be required. In this milieu of supercomputers and large-scale cloud facilities, big data processing has become convenient with platforms such as Google Earth Engine which provide users high performance computing resources through cloud. GEE has been used in this study to extract and process SAR data, as it has a large-scale analysis functionality and a catalog of satellite imageries.

\section{METHODOLOGY}

In this study, SAR data from 2014 to 2017 for three (3) reforested sites under NGP were extracted from Google Earth Engine. Additionally, three (3) samples for four (4) classes: dense forest, sparse forest, ground, and water, were made and analysed to compare their radar backscatter trends with the reforested sites' trends.

\subsection{Data Input}

\subsubsection{National Greening Program (NGP)}

The Philippines is one of the countries with the richest forest biodiversity in the world. However, it is also one of the most threatened. The country is among the most deforested in the tropics in the last 40 years, according to the study of Walpole, (2011) According to the Forest Management Bureau (FMB) of the Department of Environment and Natural Resources 
(DENR), approximately 47,000 hectares of forest cover is being lost every year. The forest cover in 2003 accounts to 7.2 million hectares, but in 2010 , this number went down to 6.8 million hectares. This accounts to less than 24 percent of the original forest cover from 1900s. Wertz-Kanounnikoff and KongphanApirak (2008) has shown that the key-drivers of deforestation in the Philippines are widespread logging, both legal and illegal. Since 2015, deforestation in the Philippines has decreased through government initiatives and increased law enforcement. According to the United Nation's Food and Agriculture Organization (FAO) 2015 Global Forest Resources Assessment, the country has increased its forest area by 240,000 hectares per year from 2010 to 2015 . This is attributed to the government's massive forest rehabilitation program, the National Greening Program (NGP). The NGP seeks to plant 1.5 billion trees in 1.5 million hectares of forest lands in the country for a period of six (6) years, from 2011 to 2016 . The main objective of NGP is reforestation, to address poverty reduction, food security, environmental stability, biodiversity conservation, and climate change mitigation and adaptation. As of 2017, this program boasts that 1.6 million hectares of forest lands have been rehabilitated. Now called Enhanced National Greening Program (ENGP), it aims to rehabilitate the remaining unproductive, denuded, and degraded forestlands from 2016 to 2028.

\subsubsection{Site Descriptions}

The select NGP data used in this study were acquired from the Department of Environment and Natural Resources (DENR), Digital Imaging for Monitoring and Evaluation - Monitoring and Assessment of Planting Activities and other Applications (DIME - MAPA) Project, and PHIL-LIDAR 2: Nationwide Detailed Resources Assessment - Forest Resource Extraction from LiDAR Surveys (FRExLS) Project.

\subsubsection{Ubay, Bohol}

The Bohol NGP site located at Barangay San Pascual, Ubay, Bohol was ground validated by the FRExLS team on November 7-16, 2016. This site was established in 2011 with Mangium (Acacia Mangium), Auri, and Teak, with minimal planting of Ipil-Ipil and Mahogany (Swietenia macrophylla). The size of the site was 2.4 hectares, with 1,716 geo-tagged trees. The slope of the site is uneven, lying on the mountain slopes.

\subsubsection{Ipil, Zamboanga Sibugay}

The Zamboanga Sibugay site located at Barangay Calula, Roseller T Lim, Zamboanga Sibugay was ground validated by the DIME-MAPA team on February 25 - March 6, 2019. The 1.35-hectare site with 1,149 inventoried trees is $82.8 \%$ composed of Rubber (Hevea brasiliensis). Other species in site are: Banana (Musa acuminata), Coconut (Cocos nucifera), and Gmelina (Gmelina arborea). The site lies on a flat terrain.

\subsubsection{Basay, Negros Oriental}

The Negros Oriental site located at Barangay Cabatuanan, Basay, Negros Oriental was ground validated by the DIMEMAPA team on February 4-13, 2019. The 1.1-hectare site with 1,416 geo-tagged trees is composed of $92.4 \%$ Mangium (Acacia Mangium) trees. The only other species in the area is Agboy (Mussaenda philippica). The site lies on uneven mountain slopes, ranging from $50-120 \%$ grade.

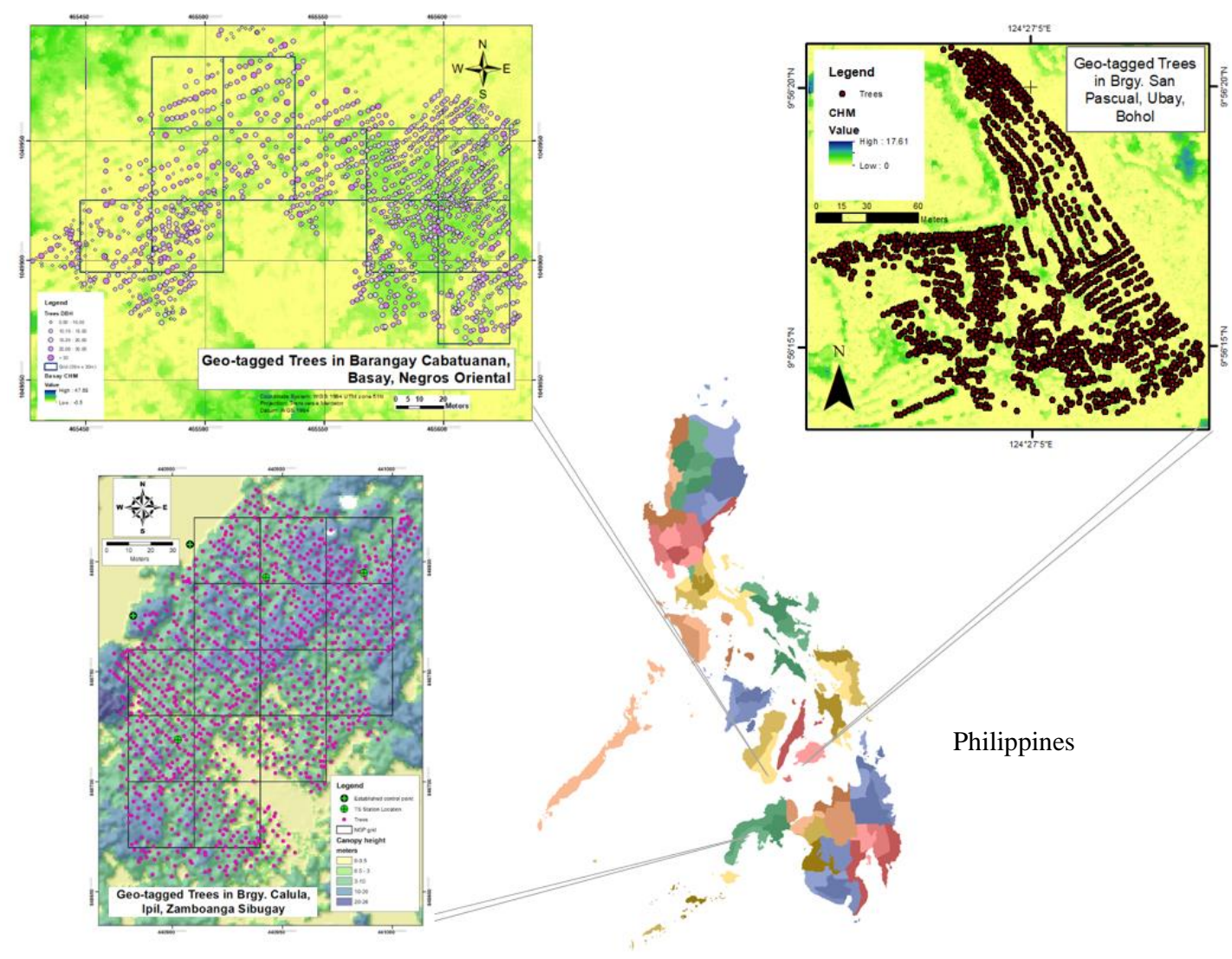

Figure 1. Location map of the study areas. Corresponding geo-tagged trees map of the NGP sites in Bohol, Zamboanga Sibugay, and Negros Oriental are included. 


\subsection{Google Earth Engine}

\subsubsection{Sentinel-1A SAR Data}

Earth Engine has a collection of Sentinel-1 Level 1 Ground Range Detected (GRD) images processed to backscatter coefficient $\left(\sigma^{\circ}\right)$ expressed in decibels $(\mathrm{dB})$. The default preprocessing steps applied were:

- Apply Orbit file

- GRD border noise removal

- Thermal noise removal

- Radiometric calibration

The whole image collection available from 2014 to 2017 for the three (3) sites and from 2014 to 2018 for the select samples were accessed and processed on GEE. The data from 76 imageries from October 14, 2014 to December 21, 2017, and from 106 imageries from October 14, 2014 to October 24, 2018, were used in the study.

\subsubsection{Data Processing}

Since no filtering was applied yet on the Sentinel-1A data, a speckle filtering algorithm was also added on the code in Earth Engine to remove speckle. The Speckle filter applied was Refined Lee which is a well-known filter for despeckling and enhancing of SAR images, according to Yommy, Lim, \& Wu, (2015). The code for Refined Lee used is based from the work of Guido Lemoine, who adapted the Refined Lee speckle filter as coded in SNAP 3.0 S1TBX, in GEE.

The filtered temporal radar backscatter data expressed in $\mathrm{dB}$ were extracted and then plotted using Matplotlib. The resolution used was $10 \mathrm{~m} \times 10 \mathrm{~m}$.

\subsection{Time Series Analysis}

2.3.1 Samples for dense forest, sparse forest, ground and water

In order to model dense and sparse forest on multi-temporal SAR images, samples for different classes were made for dense forest, sparse forest, water, and ground in Bohol. $10 \mathrm{~m} \times 10 \mathrm{~m}$ sampling was done was done using the canopy height model (CHM) generated from LiDAR from FRExLS, and by using PLANET images with up to 3-meters resolution. Three (3) samples per class were made. Their radar backscatter temporal data were extracted from GEE and then plotted. The purpose of performing analysis with these samples is to provide an idea of the possible backscatter ranges of different cover types, which will aid in the qualitative assessment of the NGP sites' radar backscattering.

\subsubsection{Analysis of the NGP sites}

The C-band radar temporal signature for Bohol, Zamboanga Sibugay, and Negros Oriental NGP sites were plotted. Analysis based on site knowledge, radar temporal signature, and corresponding rainfall and temperature data from Philippine Atmospheric, Geophysical and Astronomical Services Administration (PAG-ASA) were done.

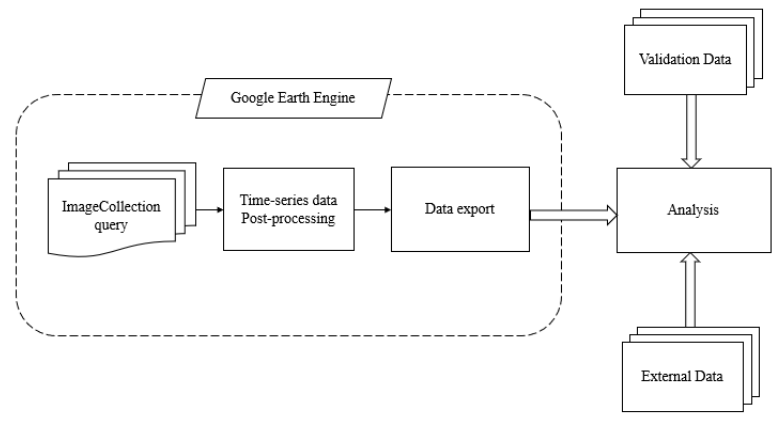

Figure 2 General overview of the methodology

\section{RESULTS AND DISCUSSION}

Google Earth Engine was used to extract Sentinel-1A data for the sites and sample classes from multiple radar images (from 2014 to 2017). The regions of interest are defined in the code as a geometry. To get the mean of the pixel values in the specified region on the image collection of interest, reducers were used. After aggregating the data, a Refined Lee filter was applied. The processed radar temporal data from 76 and 106 images, respectively, were then exported. Additional normalization was done to improve the time-series data.

\subsection{Time-series analysis of sample classes}

The corresponding Speckle Filtered and normalized temporal signatures for the sample classes are shown at Figures 3 and 4. There is one graph each for $\mathrm{VV}$ and $\mathrm{VH}$ polarization, and each line on a graph correspond to one sample. Every line corresponds to the radar temporal backscatter of each sample from 2014 to 2018. There are three (3) samples per class. For better representation, results were expressed in boxplots.

On the study made by the Committee on Earth Observation Satellites (CEOS) in 2015, they have summarized and compared the backscatter values of different land cover types in L-band (ALOS-2) and C-band (Sentinel-1). However, their study was limited, only using single-date images in their analysis. Their results show dense tropical homogenous forest in Colombia to have a C-band -12.4 (+/- 1.9) dB response in VH, and -6.2 (+/$1.0) \mathrm{dB}$ in $\mathrm{VV}$. Areas with deforestation and secondary forest growth have a -13.1 (+/- 1.4) DB response in $\mathrm{VH}$, and -8.4 (+/1.7) DB in VV. Agriculture composed of dryland crops, in Switzerland, have $-17.8(+/-2.6) \mathrm{dB}$ in $\mathrm{VH}$, and $-11.3(+/-2.3)$ $\mathrm{DB}$ in VV. Rangeland and pastures, composed of different vegetation (e.g. grass), in Brazil, have -19.4 (+/- 2.7) dB in VH, and $-12(+/-2.3) \mathrm{dB}$ in VV. Open water have $-22.5(+/-1.5) \mathrm{dB}$ in $\mathrm{VH}$, and $-17.5(+/-5) \mathrm{dB}$ in VV. Lastly, rough and uneven terrain in Kenya have $-18.4(+/-3.1) \mathrm{dB}$ in $\mathrm{VH}$, and $-8.3(+/-2)$ $\mathrm{dB}$ in VV. For comparison, the resulting backscatter values of the samples in this study are shown at Figures 7 and 8.

From the boxplots on Figures 5 and 6, water (blue) samples are easily separable from the rest, in $\mathrm{VH}$ and VV signals. These samples are taken from Bayongan Lake in Ubay, Bohol. On a SAR image, the lake looks dark, with the interpretation that the water body is a smooth surface, hence, the specular reflection. Solbø and Solheim (2005) and Braun (2017) have shown that in the case of calm and open water bodies, the incoming microwave signal is reflected at the surface. Due to the radar sensors' side-looking geometry, majority of the reflected signals are heading in to the look direction, instead of returning to the sensor. This is the reason why water exhibit low backscatter values $(\sim-20 \mathrm{~dB})$. In $\mathrm{VH}$, the water samples' inter-quartile 
range, as well as their median have high agreement with each other. In VV, the water samples' median are close, yet, their boxes are uneven in size. It is also interesting to note, that while the boxes for water have relatively high agreement in both $\mathrm{VH}$ and $\mathrm{VV}$, their whiskers are long, which means that the backscatter values outside of the middle $50 \%$ stretch over a wide range. Referring to Figure 4, the water samples' signatures overlap but their overall radar temporal signatures, after applying speckle filter and minimal normalization, are still erratic.

Dense forest, sparse forest, and ground samples were made in Ubay, Bohol using the LiDAR derived Canopy Height Model (CHM) and geo-tagged trees in 2016 from FRExLS, and PLANET satellite imageries. $10 \mathrm{~m} \times 10 \mathrm{~m}$ pixels with high CHM values around 20-40 meters, were considered for dense forest samples. This is based on the assumption that adjacent pixels with high CHM are fully covered by the forest canopies as the CHM resolution is $1 \mathrm{~m} \times 1 \mathrm{~m}$. For sparse forest, $10 \mathrm{~m} \times 10 \mathrm{~m}$ pixels with less CHM values around 10 meters, and are partially-covered by forest canopies were chosen. This is based on the assumption that sparse sample pixels have a fractional cover comprising of trees, soil, and undergrowth (e.g. grass). For ground samples, PLANET images and Google Earth were used to confirm that the samples are consistent bare soil for the period of study.
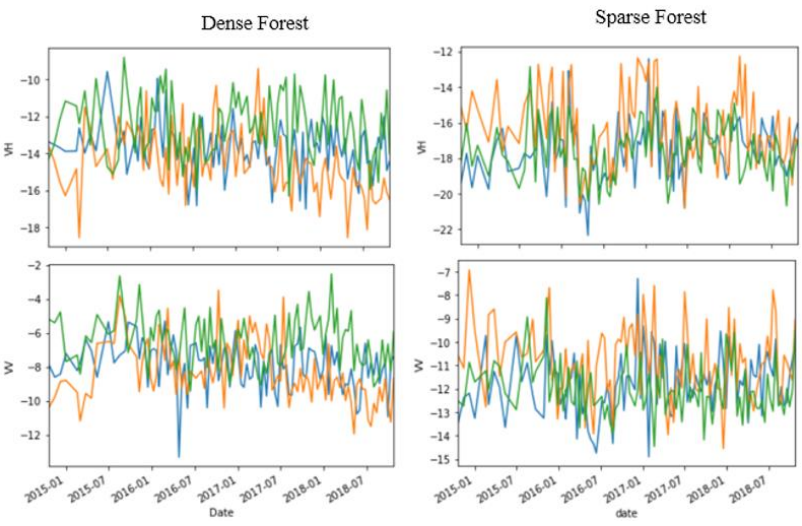

Figure 3. The temporal signature of dense forest samples (L) and sparse forest samples (R), in VH and VV.
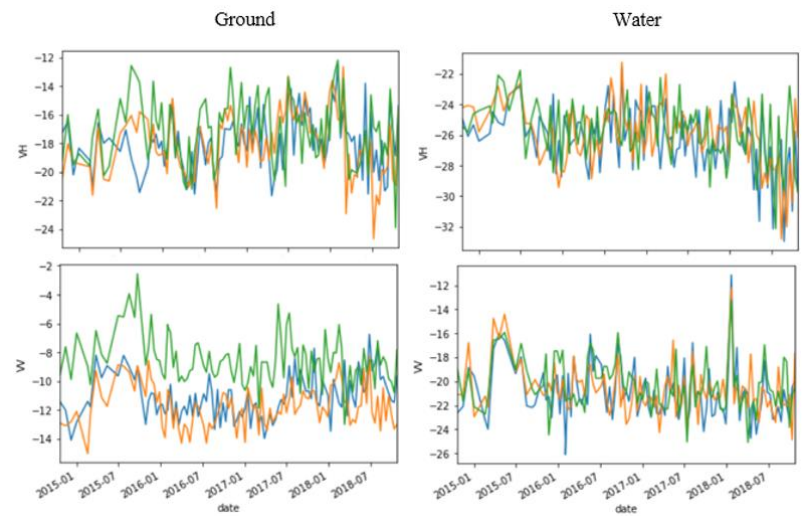

Figure 4. The temporal signature of ground samples (L) and water samples (R), in VH and VV.

The inter-quartile range of dense (green) samples are higher than sparse (yellow) samples, but sparse and ground (red) samples' range are overlapping, in VH. Sparse forest and ground samples have a very high agreement in $\mathrm{VH}$, with their medians being close. Similarly, in VV, the inter-quartile range of dense samples are higher than sparse, but sparse and ground ranges are still overlapping, but not as high in agreement as in VH.

In C-band wavelength, the radar signal scatter directly on the leaves of the dense forest canopy without penetrating deeper through the foliage. Mature dense tropical forests are expected to have uniform radar temporal signature in both $\mathrm{VH}$ and $\mathrm{VV}$ (CEOS, 2018), but as shown on Figure 3, this is not always the case. However, the median values of the dense forest samples range from -12.34 to $-13.69 \mathrm{DB}$ in $\mathrm{VH}$ and from -6.49 to -7.78 $\mathrm{DB}$ in $\mathrm{VV}$, which are relatively close to the values from the study conducted by CEOS.

C-band wavelength is highly sensitive to grasses and low vegetation, which has a strong response at both $\mathrm{VH}$ and VV. (CEOS, 2018) However, presence of different vegetation, with varying structure and growth stages, will affect the response at both VH and VV. Sparse forest samples' median are around -17 $\mathrm{DB}$ in $\mathrm{VH}$, and around -11 to $-12 \mathrm{DB}$ in $\mathrm{VV}$, which are close to the ranges for agricultural dryland crops and pasture grasslands by CEOS.

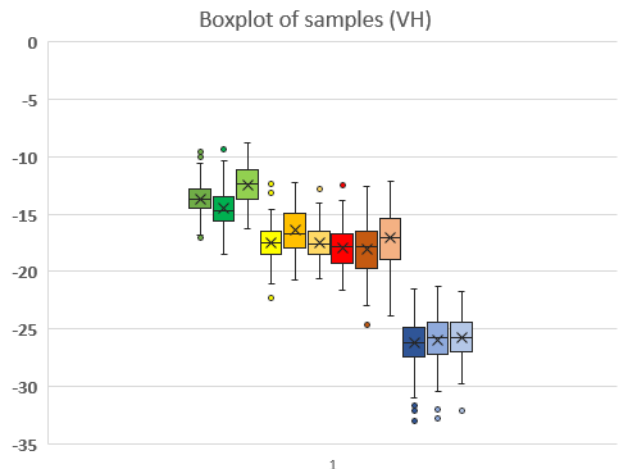

Figure 5. Box-plot of samples in VH polarization (dB). Green samples are dense forest samples, yellow-orange are sparse forest samples, red-brown are ground samples, and blue are water samples.

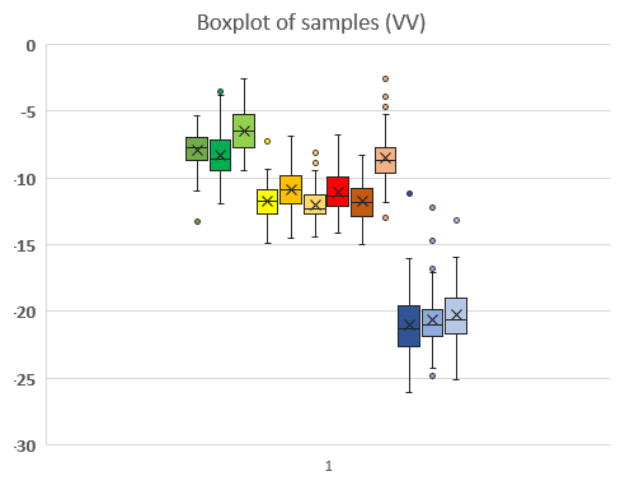

Figure 6. Box-plot of samples in VV polarization $(\mathrm{dB})$

However, the sparse forest and ground samples' ranges are overlapping. This might be caused by the selected samples for ground, because they might actually have low vegetation, which the C-band wavelength is sensitive of. C-band rocky terrain were identified to have high values at $\mathrm{VV}$, around $-8 \mathrm{~dB}$, and have moderate values at $\mathrm{VH}$, around $-18 \mathrm{~dB}$. The results for the ground samples are also close to the identified values by the CEOS study, with around $-17 \mathrm{~dB}$ in $\mathrm{VH}$, and around -8 to -11 $\mathrm{dB}$ in VV. Further research with better sampling, matched with 
periodic ground validation, is recommended to analyze the radar backscattering of different land cover types. It is very important to have a good site knowledge for analysis, since local vegetation characteristics, local weather, and seasonal conditions at the time of acquisition, greatly affect the backscatter.

\begin{tabular}{|l|c|c|c|c|c|c|}
\hline Sample & $\begin{array}{c}\text { minimum } \\
\text { value }\end{array}$ & $\begin{array}{c}\text { first } \\
\text { quartile }\end{array}$ & median & $\begin{array}{c}\text { third } \\
\text { quartile }\end{array}$ & $\begin{array}{c}\text { maximum } \\
\text { value }\end{array}$ & $\begin{array}{c}\text { standard } \\
\text { dev }\end{array}$ \\
\hline dense 1 & -17.01 & -14.43 & -13.69 & -12.85 & -9.56 & 1.36 \\
\hline dense2 & -18.56 & -15.60 & -14.74 & -13.49 & -9.39 & 1.73 \\
\hline dense3 & -16.30 & -13.75 & -12.34 & -11.19 & -8.79 & 1.67 \\
\hline sparse1 & -22.34 & -18.48 & -17.52 & -16.54 & -12.41 & 1.67 \\
\hline sparse2 & -20.79 & -17.95 & -16.74 & -14.96 & -12.25 & 2.14 \\
\hline sparse3 & -20.68 & -18.51 & -17.66 & -16.53 & -12.84 & 1.54 \\
\hline ground1 & -21.67 & -19.24 & -17.86 & -16.75 & -12.50 & 1.98 \\
\hline ground2 & -24.68 & -19.66 & -17.83 & -16.50 & -12.65 & 2.19 \\
\hline ground3 & -23.90 & -18.93 & -17.03 & -15.39 & -12.18 & 2.31 \\
\hline water1 & -32.97 & -27.34 & -26.16 & -24.95 & -21.55 & 2.03 \\
\hline water2 & -32.81 & -27.19 & -25.79 & -24.45 & -21.24 & 1.98 \\
\hline water3 & -32.14 & -26.88 & -25.76 & -24.41 & -21.76 & 1.89 \\
\hline
\end{tabular}

Figure 7. VH backscatter values of the samples (dB), from the boxplot from Figure 5.

\begin{tabular}{|c|c|c|c|c|c|c|}
\hline \multicolumn{7}{|c|}{ VV polarization } \\
\hline Sample & $\begin{array}{c}\text { minimum } \\
\text { value }\end{array}$ & $\begin{array}{c}\text { first } \\
\text { quartile }\end{array}$ & median & $\begin{array}{c}\text { third } \\
\text { quartile }\end{array}$ & $\begin{array}{c}\text { maximum } \\
\text { value }\end{array}$ & $\begin{array}{c}\text { standard } \\
\text { dev }\end{array}$ \\
\hline dense1 & -13.33 & -8.73 & -7.78 & -7.00 & -5.31 & 1.36 \\
\hline dense2 & -11.96 & -9.42 & -8.62 & -7.20 & -3.49 & 1.74 \\
\hline dense3 & -9.44 & -7.68 & -6.49 & -5.27 & -2.53 & 1.46 \\
\hline sparse1 & -14.90 & -12.67 & -11.79 & -10.94 & -7.30 & 1.34 \\
\hline sparse2 & -14.55 & -11.97 & -10.92 & -9.90 & -6.93 & 1.52 \\
\hline sparse3 & -14.46 & -12.73 & -12.28 & -11.27 & -8.11 & 1.14 \\
\hline ground1 & -14.10 & -12.12 & -11.32 & -10.03 & -6.76 & 1.50 \\
\hline ground2 & -15.04 & -12.90 & -11.83 & -10.84 & -8.30 & 1.42 \\
\hline ground3 & -13.01 & -9.66 & -8.68 & -7.73 & -2.55 & 1.67 \\
\hline water1 & -26.11 & -22.65 & -21.29 & -19.61 & -11.15 & 2.27 \\
\hline water2 & -24.88 & -21.85 & -21.06 & -19.86 & -12.20 & 2.03 \\
\hline water3 & -25.09 & -21.65 & -20.66 & -19.01 & -13.22 & 2.08 \\
\hline
\end{tabular}

Figure 8. VV backscatter values of the samples $(\mathrm{dB})$, from the boxplot in Figure 6.

\subsection{Backscatter Time Series Analysis of NGP sites}

The corresponding time-series plot of Bohol, Zamboanga Sibugay, and Negros Oriental NGP sites are shown at Figure 9. Provided are the sites' mean backscatter from 2014 to 2017 in $\mathrm{VH}, \mathrm{VV}$, and ratio of $\mathrm{VH} / \mathrm{VV}$. Also included below the graphs are the corresponding rainfall and temperature plots, per site. Daily Rainfall and Temperature were acquired from PAG-ASA. Rainfall $(\mathrm{mm})$ and Temperature graph will serve as reference, whether changing environmental conditions affect radar backscattering, according to the study by Dostalova, Milenkovic, Hollaus, \& Wagner, (2016).

Referring to Figure 9, the temporal signatures of the NGP sites are grouped by date, hence the obvious discontinuity at some points. Blue lines are 2014 data; yellow for 2015, green for 2016, and red for 2017. The temporal signature was grouped by years, for easier discussion and visualization of changes in radar backscatter, since the sites are growing reforestation sites established from 2011 and 2012. By 2014, these forests are around 2- 3 years old.

Among the three sites, the Zamboanga Sibugay NGP site is the most ideal, as it lies on a flat terrain and it is a homogenous rubber-plantation. This site fits a good regular shape covering dense forest cover, which will be reduced well when aggregated using ee.reduceRegion on Google Earth Engine. This means that with its shape, the reduction and averaging of backscatter for its area will only include dense forest cover. This is unlike the shape of Negros Oriental, for example, which is spread out, and will include adjacent pixels without much forest cover on its region aggregation. According to the study by CEOS (2015), forest plantations of rubber in Vietnam have a $-12.8(+/--1.1)$ $\mathrm{dB}$ in $\mathrm{VH}$ and $-6.5(+/--1.2) \mathrm{DB}$ in VV. The temporal signatures of the Zamboanga Sibugay site, in both $\mathrm{VH}$ and VV, are within this range. Also, these temporal signatures fall within the range of the dense forest samples identified previously. Rubber trees are of deciduous forest type, with leaf sizes up to $13-15 \mathrm{~cm}$ which are larger than the C-band wavelength. The dominant backscatter mechanism will be direct canopy scattering (in C-band) because the leaves of the dense forest canopy will cause direct scattering, where the transmitted signal is reflected directly back to the sensor.

Looking at Figure 9, all three sites are forested, however, only Zamboanga Sibugay and Negros Oriental sites, have a similarity in their trends and have closer backscatter ranges to dense forest samples. They both have a peak towards the end of year 2015 (yellow line), then a big drop in early 2016 (green line), and then increase in backscatter again and maintain the variation of around $2 \mathrm{~dB}$ until 2017 (red line), at both VH and VV. The Bohol NGP site's temporal signature fall within the identified range of sparse forest samples. This might be caused mainly by the heterogeneity of species planted, and the uneven planting on the site caused by steep slopes. The dominant backscatter mechanism here would be diffuse scattering, where the signal is scattered into different directions. Again, this is because C-band is sensitive to the presence of different vegetation with varying structure and growth stages, which affects the backscatter. Comparing with the Negros Oriental sites' radar temporal signature, its values still fall within the range of dense forest samples even if it is situated on a very steep slope too. The majority of the trees planted on it are Mahogany trees, which are fast-growing, with an increase in height of 3-4 feet per year. This indicates that the slope of the terrain and height of trees, are not the major factors affecting backscatter, but the homogeneity or heterogeneity of species planted and the planting spacing (with too much undergrowth) are.

Dense and sparse forests' mean values are, in $\mathrm{VH}$ : $-13.59 \mathrm{~dB}$ and $-17.31 \mathrm{DB}$, and in $\mathrm{VV}:-7.63 \mathrm{DB}$ and $-11.66 \mathrm{~dB}$, respectively. It is hard to completely separate the two by just using the ranges as reference, since they have around 1-3 dB variation in $\mathrm{VH}$, and around $1-4 \mathrm{~dB}$ variation in $\mathrm{VV}$, where their radar backscatter values overlap in the overall temporal signature. 
Ubay, Bohol
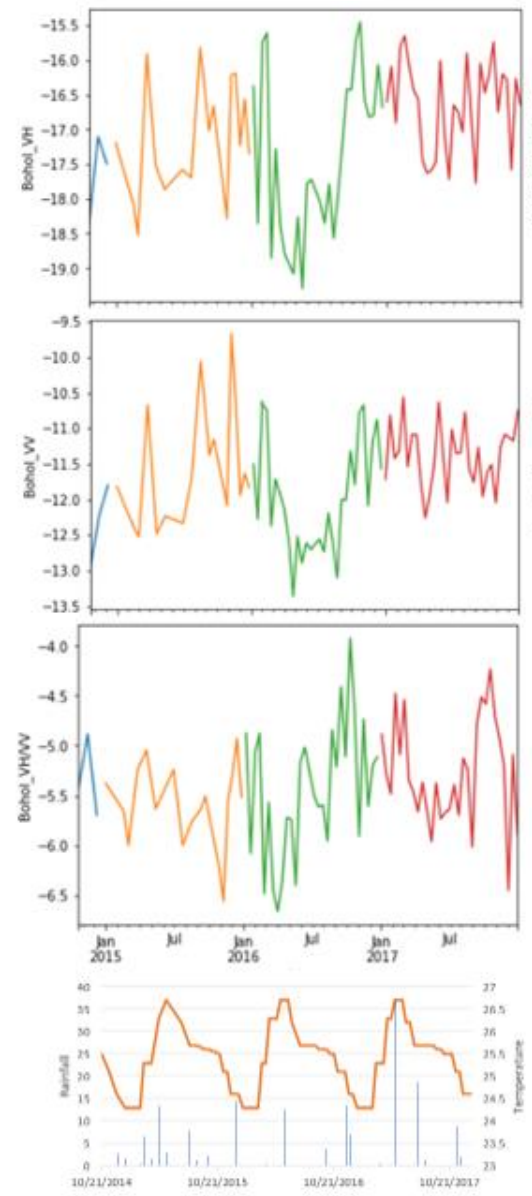

RT Lim, Zamboanga Sibugay
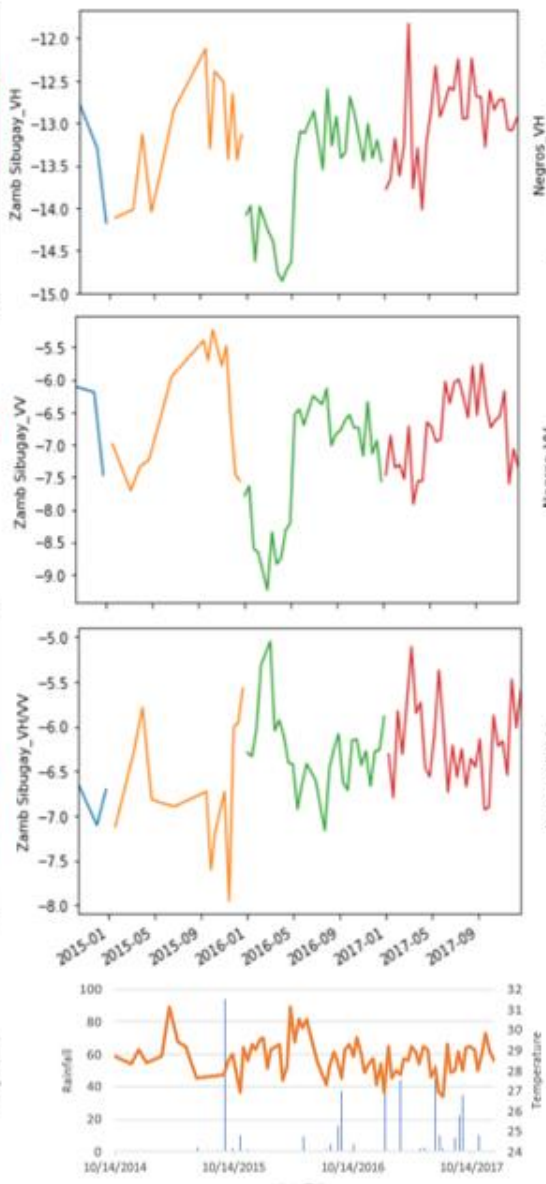

Cabatuanan, Negros Oriental
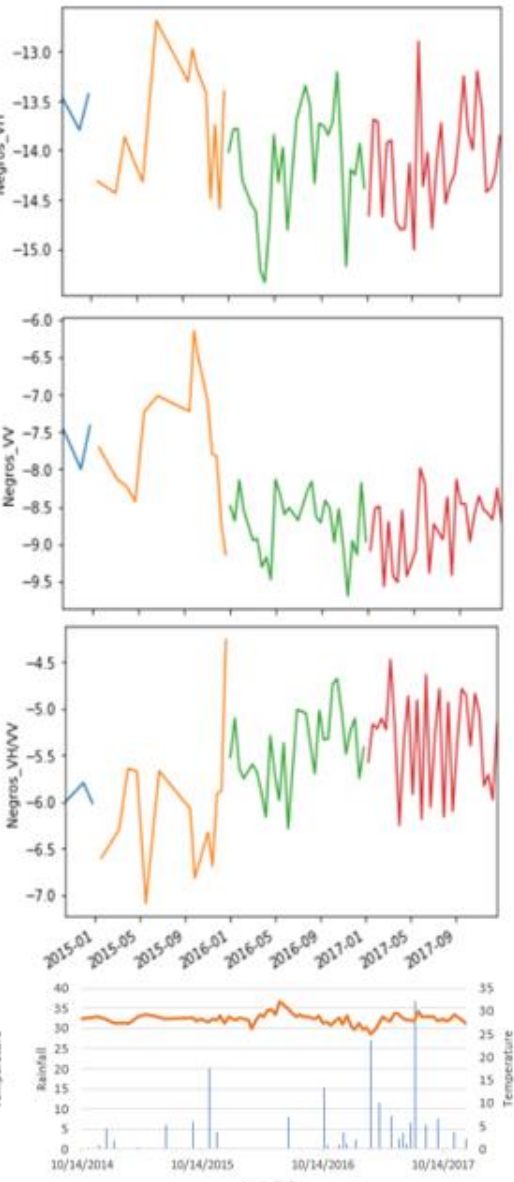

Figure 9. (From left) Temporal signature of Bohol, Zamboanga Sibugay, and Negros Oriental NGP sites. Provided are (from top to bottom) their plots in $\mathrm{VH}(\mathrm{dB}), \mathrm{VV}(\mathrm{dB}), \mathrm{VH} / \mathrm{VV}$, rainfall $(\mathrm{mm})$, and temperature (Celsius). The temporal signature for $\mathrm{VH}$, VV, and VH/VV are grouped and color-coded by year: blue (2014), yellow (2015), green (2016), and red (2017).

\section{CONCLUSION}

However, in terms of trend, dense forests have higher backscatter response compared to sparse forests because of the scattering mechanisms they exhibit. Dense forests are mostly influenced by direct scattering, whereas sparse forests are mostly influenced by diffuse scattering. Recall, the three sites were established in 2011, which indicates that they are around 3 years old in 2014. Looking back at the trend of their temporal signatures in Figure 9, they all started with a fairly low backscatter in 2015, going up until the end of the year. This trend is repeated again, when the sites are 5 years old, in year 2016. From the increase in magnitude from the end of 2015, the sites' radar backscatter dropped significantly as the summer season ends, in the Philippines. The summer season in the country is from November to May, while the rainy season is from June to October. These significantly low radar backscatter values in summer 2016 increased, as the rainy season started. The trend repeated again in 2017, subtlety, unlike in 2016. The drop in radar backscatter is still present as the summer ends, and increased again as the rainy season started. However, the values at this point are not as varying anymore. This may be attributed to the saturation of forest signals. Joshi, et. al (2017) has shown in their study that there is an increase in backscatter due to changes in forest properties such as increasing stem sizes, which are compensated by an equal decrease in the magnitude, caused by other properties like increase in tree height, contributing to the saturation of radar signals over forest.
Google Earth Engine was used to derive the C-band Sentinel1A radar temporal data of select sample sites (dense forest, sparse forest, ground, and water) and the reforestation sites in Ubay, Bohol, Zamboanga Sibugay, and Negros Oriental from 2014 onwards. For dense forest samples, the typical backscatter ranges from -11 to $-18 \mathrm{~dB}$ in $\mathrm{VH}$ and -2 to $-13 \mathrm{~dB}$ in $\mathrm{VV}$. Sparse forest samples range from -12 to $-21 \mathrm{~dB}$ in $\mathrm{VH}$ and -7 to $-14 \mathrm{~dB}$ in VV. Ground samples range from -12 to $-24 \mathrm{~dB}$ in $\mathrm{VH}$ and -6 to $-15 \mathrm{~dB}$ in VV. Water samples, on the otherhand, range from -21 to $-30 \mathrm{~dB}$ in $\mathrm{VH}$ and -11 to $-26 \mathrm{~dB}$ in $\mathrm{VV}$. However, as seen from the boxplots showing the distribution, median, and variability of radar backscatter of each samples, it is difficult to fully distinguish dense forest signals from sparse forest.

Forest type, homogeneity of species planted, and seasonal behaviour are three of the major factors contributing to the backscattering variation on forests' temporal signature. Forest backscatter are also expected to saturate over time, especially in dense forests. The variations are due to differences in forest species, landscape, environmental and climatic drivers, and phenomenon or interventions on the site. For further research, it is suggested to have better sampling, site knowledge, ground data, and separate analysis of data by known forest type (coniferous, deciduous), structure, and season. It is also 
suggested to have additional external data such as forest cover fraction, height, and structure for modelling.

\section{ACKNOWLEDGEMENTS}

The authors would like to thank the Department of Environment and Natural Resources (DENR), Department of Budget and Management (DBM), Digital Imaging for Monitoring and Evaluation - Monitoring and Assessment of Planting Activities and other Applications (DIME - MAPA) Project, PHIL-LIDAR 2: Nationwide Detailed Resources Assessment - Forest Resource Extraction from LiDAR Surveys (FRExLS) Project, and Philippine Atmospheric, Geophysical and Astronomical Services Administration (PAG-ASA) for the data used in this study.

\section{REFERENCES}

Braun, A., 2017. SAR images show water in dark tone. Is it due to reflection or absorption? Retrieved from ResearchGate: https://www.researchgate.net/post/SAR_images_show_water_in _dark_tone_Is_it_due_to_reflection_or_absorption

CEOS, 2018. A Layman's Interpretation Guide to L-band and C-band Syntheic Aperture Radar (SAR). Retrieved from Committee on Eaarth Observation Satellites (CEOS):http://ceos.org/document_management/SEO/DataCube/ Laymans_SAR_Interpretation_Guide_2.0.pdf

CIFOR, 2010. The operational role of remote sensing in forest and landscape management: Focus group discussion proceedings. Bogor, Indonesia: Center for International Forestry Research (CIFOR)

Dostalova, A., Hollaus, M., Milenkovic, M., \& Wagner, W., 2016. Forest Area Derivation from Sentinel-1 data. ISPRS Annals of the Photogrammetry, Remote Sensing and Spatial Information Sciences, 227-233.

Dostalova, A., Milenkovic, M., Hollaus, M., \& Wagner, W., 2016. Influence of Forest Structure on the Sentinel-1 Backscatter Variation - Analysis with Full-Waveform Lidar data. Living Planet Symposium. Prague.

FAO. (n.d.). DEFORESTATION AND FOREST DEGRADATION FACTORS. Retrieved from Food and Agriculture Organization of the United Nations: http://www.fao.org/3/xii/ms12a-e.htm

Gorelick, N., Hancher, M., Dixon, M., Ilyushchenko, S., Thau, D., \& Moore, R., 2017. Google Earth Engine: Planetary-scale geospatial analysis for everyone. Remote Sensing of Environment, 202, 18-27.

Greentumble, 2016. The Problem of Illegal Logging in Philippines. Retrieved from Greentumble: https://greentumble.com/the-problem-of-illegal-logging-inphilippines/

Joshi, N., Mitchard, E., Brolly, M., Schumacher, J., FernandezLanda, A., Johannsen, V., . . . Fensholt, R., 2016. Understanding 'saturation' of radar signals over forests. Nature.

Lemoine, G., 2018. Retrieved from Google Earth Engine: https://code.earthengine.google.com/a8dBe1d32b2838764003d 09afa30189b

Nasirzadehdizaji, R., Balik Sanli, F., Abdikan, S., Cakir, Z., Sekertekin, A., \& Ustuner, M., 2019. Sensitivity Analysis of
Multi-Temporal Sentinel-1 SAR Parameters to Crop Height and Canopy Coverage. Applied Science, 655.

Periasamy, S., 2018. Significance of dual polarimetric synthetic aperture radar in biomass retrieval: An attempt on Sentinel-1. Remote Sensing of the Environment, 217, 537-549.

Philippine Star. 2018. Recovering the Philippines' forest cover. Retrieved from Philstar Global: https://www.philstar.com/headlines/2018/03/04/1793446/recove ring-philippines-forest-cover

SERVIR, 2019. The Synthetic Aperture Radar(SAR) HandBook: Comprehensive Methodologies for Forest Monitoring and Biomass Estimation. Huntsville, Alabama: SERVIR Global Science Coordination Office. Retrieved from https://servirglobal.net/Global/Articles/Article/2674/sarhandBook-comprehensive-methodologies-for-forestmonitoring-and-biomass-estimation

Solbø, S., \& Solheim, I., 2005. Towards Operational Flood Mapping with Satellite SAR. European Space Agency (Special Publication).

Tomppo, E., Praks, J., Wang, G., \& Waser, L., 2019. Special Issue "Advances in Remote Sensing for Global Forest Monitoring". Advances in Remote Sensing for Global Forest Monitoring .

Vyjayanthi, N., Jha, C., Murthy, M., Yadav, D. K., \& Singh, L., 2008. Forest Biomass Estimation and Forest Structure Analysis of deciduous Forests using SAR data. Hyderabad: National Remote Sensing Centre (NRSC) Hyderabad.

Wagner, W., 2016. Time Series Analysis of Sentinel-1 Backscatter on a High Performance Computing Platform. Retrieved from Geostatistics and Machine Learning Applications in Climate and Environmental Sciences: http://geomla.grf.bg.ac.rs/site_media/static/presentations/day_1/ keynote/Wagner_Sentinel-

$1 \% 20$ Time\%20Series\%20Analysis.pdf

Walker, W., 2016. Introduction to RADAR Remote Sensing for Vegetation Mapping and Monitoring. Retrieved from Woods Hole Research Center: http://whrc.org/wpcontent/uploads/2016/02/Walker_SAR_Veg_Mapping.pdf

Walpole, P., 2011. Low forest cover in the Philippines : Issues and responses at the community level. Retrieved from Environmental Science for Social Change, Inc. (ESSC): https://essc.org.ph/content/lview/579/1/

Wertz-Kannounikoff, S., \& Kongphan-Apirak, M., 2008. Reducing forest emissions in Southeast Asia: A reviewof drivers of land-use change and how payments for environmental services (PES) schemes can affect them. Center for International Forestry Research (CIFOR).

White, J., Coops, N., Wulder, M., Vastaranta, M., Hilker, T., \& Tompalski, P., 2016. Remote Sensing Technologies for Enhancing Forest Inventories: A Review. Canadian Journal of Remote Sensing, 42(5), 619-641.

Yommy, A. S., Lim, R., \& Wu, S., 2015. SAR Image Despeckling using Refined Lee Filter. 7th International Conference on Intelligent Human-Machine Systems and Cybernetics (pp. 260-265). IEEE. 